\title{
Development of Solar Operated Sprayer for Small Scale Farmers
}

\author{
Ashutosh Mishra ${ }^{1}$, Neetu Bhagat ${ }^{2}$ and Padam Singh ${ }^{3 *}$ \\ ${ }^{1}$ SCRIET CCS University Campus Meerut, India \\ ${ }^{2}$ Deputy Director Approval, Bereau AICTE New Delhi, India \\ ${ }^{3}$ College of Forestry, Veer Chandra Singh Garhwali Uttarakhand, Ranichauri, \\ Tehri Garhwal (Uttarakhand), India \\ *Corresponding author
}

\section{A B S T R A C T}

\section{Keywords}

Solar operated sprayer,

Small scale

farmers

Article Info

Accepted:

20 January 2019

Available Online:

10 February 2019
The cost of fuel and the effect of emission of gases from the burnt fuel into the atmosphere, this necessitated the use of the abundant solar energy from the sun as a source of power to drive a sprayer The Photovoltaic (PV) panel of $6 \mathrm{~V}, 5 \mathrm{~W}$ capacity configured to trap and convert the sun's energy into the useful power was used to perform the work of spraying. Solar PV Panel was used for operating the sprayer and for charging a battery. The motor was used to regulate spraying liquid from the sprayer tank (5 lit.) and spray it through spinning disc nozzle. The SPV operated sprayer was provided with 6volt, $4.5 \mathrm{amp}$ lead acid battery which was used as alternative power source during cloudy atmosphere (in rainy season).

\section{Introduction}

A sprayer is a mechanical device used to spray the liquid like herbicides, pesticides, fungicides and fertilizers to the crops in order to avoid any pest and control the unwanted plant species. Sprayer provides optimum utilization of pesticides or any liquid with minimum efforts. In Indian farms generally two types of spray pumps are used for spraying, they are hand operated spray pump and fuel operated spray pump, out of which hand operated spray pumps are most popular. To kill the pests and insects pesticides, fertilizers are sprayed either manually or by using sprayers. Earlier, the pesticides and fertilizers were sprinkled manually, but they will result in harmful effects on farmers. In order to overcome this problem, different spraying techniques have been developed. These sprayers consist of different mechanisms and the cost of equipment is generally high. A solar operated sprayer is easy to handle and maintenance free, hence is affordable to the farmers. Therefore a solar operated sprayer is designed and fabricated. This system can be operated using solar energy or electrical energy. The solar energy 
is converted into electrical energy and is stored in a storage battery. The main advantages of the present system are the running cost reduces to minimum and consume less time. Solar energy from the sun is harvested on the solar panel. The panel is made up of photovoltaic cells, which converts photon energy to electric energy. These cells are made up of silicon semiconductor. Solar panel is

\section{Development of Solar photovoltaic Operated Sprayer}

A solar photovoltaic operated sprayer consisted of different components. viz; photovoltaic panel panels, motor and control system and spray lance with spinning disc

\section{Solar photovoltaic (SPV) panel}

The Photovoltaic (PV) or solar panel of $6 \mathrm{~V}, 5$ W capacity configured to trap and convert the sun's energy into the useful power was used to perform the work of spraying. Solar PV Panel was used for operating the Sprayer and for charging a battery.

\section{D.C. Motor}

A 6 V D.C. motor was used to operate the spinning disc having 4000-4400 rpm. The D.C. motor was fitted at the end of the lance. The spinning disc nozzle was fixed on D.C. motor. A compact size, rust proof, easy to clean and maintain and low electric consumption motor was used to reduce the weight. Liquid enters on spinning disc by rotating spinning disc nozzle used the centrifugal force to add velocity to the liquid and breaks it into fine droplets.

\section{Liquid tank}

The 5 liters capacity tank made up of High density polyethylene material was used and connected to the spray lance pipe with spinning disc nozzle.

\section{Battery}

The SPV operated sprayer was provided with $6 \mathrm{~V}, 4.5$ Ah sealed lead acid battery which was used as alternative power source during cloudy atmosphere (in rainy season).

The battery was charged with the help of SPV panel available on top of the sprayers. The regularized voltage of $6 \mathrm{~V}$ required for motor operation was supplied by battery.

\section{Spinning disc nozzle}

The spinning disc nozzle was fitted on the sprayer lance. The spinning disc type nozzle breaks liquid into fine droplets. The output droplet size depends on flow rate and disc operating speed.

\section{Lance}

A lance made up of fiber material having extension rod for increasing the lance length was used. Extension rod was made up of mild steel material. The battery casing was made up of HDPE (High Density Polyethylene) material was placed at rare end of lance. The on/off switch was provided on lance. The motor was fitted on front end of lance with spinning disc.

\section{Solar Charge controller}

A solar charge controller regulated the voltage and current from solar panel. It was placed between a solar panel and a battery.

It was used to maintain the proper charging voltage to the battery and protected it from overcharging and discharging. The technical specification of developed SPV operated sprayer are summarized in 


\section{Working principle of Solar photovoltaic Operated Sprayer}

Solar operated system consists of Solar panel, battery, pump and sprayer. The solar panel delivers an output in the order of 12 volts and 20 Watts power to the charging unit. The charging unit is used to strengthen the signal from the solar panel. The charging unit delivers the signal which charges the battery. According to the charged unit, the pump operates, such that the sprayer works. Here fertilizer can be stored in tank. When the sun rays are falling on the solar panel electricity will be generated through the solar cells and stored in the battery. By the electric power in the battery the pump operates and therefore fertilizers from the tank is sprayed out through the sprayers. There is no maintenance cost and operating cost as it is using solar energy and no pollution problem (Fig. 1 and 2).

Fig.1\&2 Assembly of solar energy driven sprayer \& testing of solar energy driven sprayer

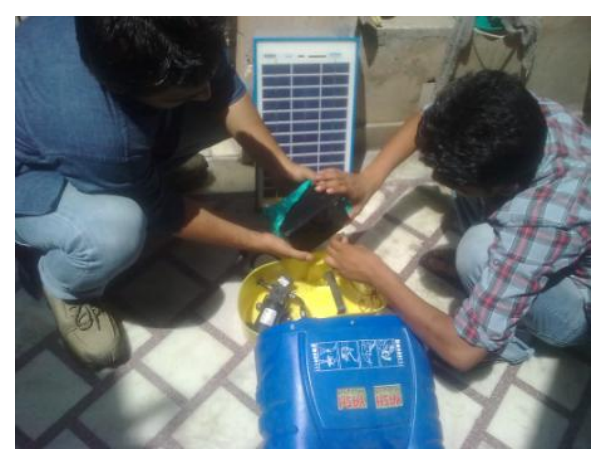

In solar energy mode, solar energy obtained by the sun is converted into electrical energy using solar panel by photovoltaic effect. The output of energy conversion was used to charge a deep cycle battery. The number of times a battery can be discharged is known as its life cycle. For solar applications, a battery should be capable of being discharged in several times. In such cases a deep cycle battery is used. In this work a lead-acid accumulator serves the purpose. The lead-acid battery has the properties such as high current availability, contact voltage, longer life and more ability to charge as compare to conventional batteries. The output of battery is connected to a DC pump through protection circuit. The DC pump is selected because of the advantages such as less in noise, longer in life, maintenance free, motor speed can be varied in the larger extent by varying the supply voltage and is self-lubricated. Pump is

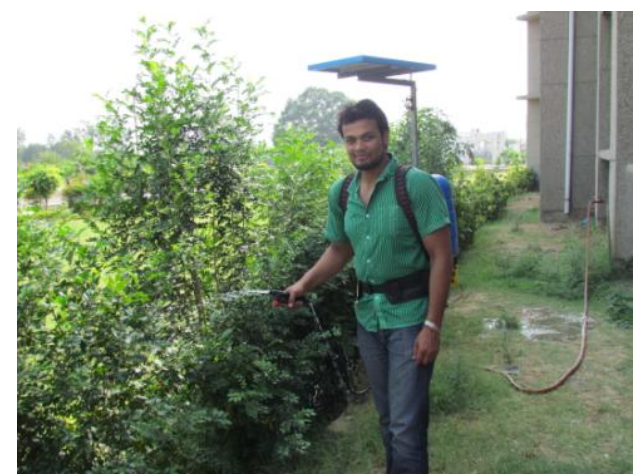

used to suck the spraying liquid from the sprayer tank and spray it through nozzle. The sprayer consists of sprayer tank and sprayer pipe. The sprayer tank is made up of plastic or fiber material in order to reduce the weight of the tank. The capacity of the tank is 16 liters and connected to the sprayer pipe with adjustable nozzle. By adjusting the nozzle the output of flow can be controlled. The whole unit can be carried conveniently at the back of human body with the help of shoulder straps. The supporting base of entire unit needs to be strong and light in weight.

The Photovoltaic (PV) panel of $6 \mathrm{~V}, 5 \mathrm{~W}$ capacity configured to trap and convert the sun's energy into the useful power was used to perform the work of spraying. Solar PV Panel was used for operating the sprayer and for charging a battery. The motor was used to operate spinning disc. The spraying liquid 
from the sprayer tank (5lit.) is led to spinning disc nozzle. The SPV operated weedicide sprayer was provided with $6 \mathrm{~V}, 4.5$ Ah sealed lead acid battery which was used as alternative power source during cloudy atmosphere (in rainy season). The newly developed SPV operated sprayer was evaluated in term of laboratory and field testing. The laboratory testing of SPV operated sprayer included charging/ discharging characteristics.

In conclusion, the prepared solar operated sprayer is environment friendly and cost efficient. This sprayer can be used largely in agriculture field effectively. It is best option to farmer who economically challenged and facing electrical problems like load shedding. It does not require fuel hence it is a zero fuel operated equipment and does not create air pollution and noise. The solar operated sprayer will help the farmers of those remote areas of country where fuel is not available easily. They can perform their regular work as well as saves fuel up to large extent. At the same time they can do their pesticide spraying work with very less environment pollution.

\section{References}

Joshua, R., V. Vasu and P. Vincent, Solar Sprayer - An Agriculture Implement, International Journal of Sustainable Agriculture 2 (1): 16-19, 2010.

Pandurang Lad, Virendra Patil, Prashant Patil, Tushar Pati, Pravin Patil, Solar operated pesticide sprayer, International Journal of Advance Research In Science And Engineering IJARSE, Vol. No.4, Special Issue (01), April 2015.

Rajesh, R., V. Vimal kingsley, M. Selva pandi, G. Niranjan, G. Varun harshath, Design and Fabrication of Solar Pesticide Sprayer, International Journal of Innovative Research in Science, Engineering and Technology, Vol. 5, Special Issue 8, 2016.

Sarvesh Kulkarni, Karan Hasurkar, Ramdas Kumbhar, Amol Gonde, Raut A.S., Review of Solar Powered Pesticide Sprayer, International Journal of Research in Advent Technology, Vol.3, No.4, April 2015.

\section{How to cite this article:}

Ashutosh Mishra, Neetu Bhagat and Padam Singh. 2019. Development of Solar Operated Sprayer for Small Scale Farmers. Int.J.Curr.Microbiol.App.Sci. 8(02): 2593-2596.

doi: https://doi.org/10.20546/ijcmas.2019.802.301 